\title{
Improving Problem-Solving Skills with the Help of Plane-Space Analogies
}

LÁSZLÓ BUDAI

$\approx$ We live our lives in three-dimensional space and encounter geometrical problems (equipment instructions, maps, etc.) every day. Yet there are not sufficient opportunities for high school students to learn geometry. New teaching methods can help remedy this. Specifically our experience indicates that there is great promise for use of geometry programs, GeoGebra and DGS, combined with plane space analogies for the development of spatial thinking and problem-solving skills in the three dimensions of solid geometry.

Keywords: Problem solving; Plane-space analogies; GeoGebra; Teaching; Secondary school

1 Budapest Business School, University of Applied Sciences, College of International Management and Business, Institute of Business Teacher Training and Pedagogy, Hungary; budaio912@gmail.com 


\section{Izboljšanje sposobnosti reševanja problemov s pomočjo prostorsko-ravninske analogije}

LÁSZLó BUDAI

$\propto$ Živimo v tridimenzionalnem prostoru in se dnevno srečujemo z geometrijskimi problemi (navodila za uporabo različne opreme, zemljevidi idr.). Po drugi strani pa učenci nimajo veliko priložnosti za učenje tovrstnih vsebin $\mathrm{v}$ šoli. $\mathrm{Z}$ oblikovanjem novih učnih pristopov pa situacijo lahko bistveno izboljšamo. $V$ prispevku prikazujemo svoje izkušnje, ki potrjujejo pomembno vlogo geometrijskih programov GeoGebra in DGS skupaj z razvijanjem prostorsko-ravninske analogije pri razvijanju prostorske predstavljivosti in reševanju problemov iz prostorske geometrije pri učencih.

Ključne besede: reševanje problemov, prostorsko-ravninska analogija, GeoGebra, DGS, poučevanje, srednješolsko izobraževanje 


\section{Introduction}

Spatial abilities are so important in modern life that several research projects addressed evaluation of these abilities in students (Gorska \& Cižmešija, 2007; Hoffmann \& Németh, 2007; Milin-Šipuš, 2012; Nagy-Kondor, 2007; Nagy-Kondor, 2012).

Cultural, social, technological and mathematical-didactical changes over the past ten years have modified the benchmarks for development of spatial perception. New teaching methods use analogies/analogues to solve several of these problems together and understand the relationships between different sets of problems (Lénárd, 1978; Pólya, 1988; Pólya, 1989).

Analogues refer to the similarity and parity between things. In geometry, we may talk about analogies between objects, theorems and problems, as well as between problem solving, proof methods and processes.

Here we deal with analogies involving the spatial (three-dimensional) generalisation of plane geometrical theorems (for other interpretations see McGee, 1979 or Nagy, 2000). Using analogy we can generalise plane geometric theorems in the plane itself and also spatial geometric theorems in three dimensions.

The examples below consider properties that are the similar for a plane object and its spatial generalisation and so establish an analogy.

The circle and the sphere are both a set of points at a given distance (the radius) from a central point, the circle in a plane and the sphere in 3 dimensions. The tetrahedron in three dimensions is a generalization of the triangle in two dimensions and the polyhedron in three dimensions is analogous to the polygon in two dimensions. Because the sides of a square are equal length sections any of its two adjacent sheets give a right triangle. The sheets of its spatial equivalent, the cube, are congruent squares, and any of its two adjacent sheets also create a right triangle. The perpendicular bisector of the segment in the plane and the perpendicular bisector of the segment plane in space are a set of points that are equidistant from the two end points of the section.

A plane geometrical object or two dimensional theorem can have two or more analogues in $3 \mathrm{D}$-space: the tetrahedron can be considered to be the analogue of the triangle as well as of the three-sided tetrahedron and the spherical triangle. Many theorems can be applied to them that are also true for the triangle. Furthermore, we can interpret the triangle not only on the spherical surface, but also on other surfaces (e.g. non-Euclidean geometries).

From these few examples, we can see how to create analogies in different ways in geometry, and many analogies can be found in secondary school 
material. However more time in the secondary school curriculum is needed for mathematics including concepts such as analogues. Table 1 contains the average secondary school class frame numbers in a year broken down into grades.

Table 1. Number of annual mathematics classes in particular secondary school grades.

\begin{tabular}{ccccc}
\hline The degree of education & \multicolumn{4}{c}{ High school education } \\
\cline { 2 - 5 } & 9. & 10. & 11. & 12. \\
\hline $\begin{array}{c}\text { Total number of mathematics class hours per } \\
\text { school year (average) }\end{array}$ & 108 & 108 & 108 & 108 \\
\hline $\begin{array}{c}\text { Total number of geometry class hours per school } \\
\text { year }\end{array}$ & 39 & 59 & 45 & 35 \\
\hline $\begin{array}{c}\text { Number of three dimensional type class hours per } \\
\text { school year }\end{array}$ & 3 & 6 & 4 & 21 \\
\hline $\begin{array}{c}\text { Percentage rate of three dimensional geometry } \\
\text { type class hours compared to the total class hours }\end{array}$ & $2,7 \%$ & $5,4 \%$ & $3,7 \%$ & $19,5 \%$ \\
\hline
\end{tabular}

Many students first encounter the pyramid in mathematics classes at the age of 18 and yet despite this slow pace of learning, the new basic educational curriculum in Hungary starting September 2013 unfortunately further reduces the time for mathematics classes.

\section{Plane-space analogies in public secondary education}

The following discussions of analogies would be valuable within the framework of the mathematics curriculum:

- definition of the concept of planar and spatial objects, their mutual position and their distance (for example, the distance of two straight lines and the distance of two planes or the distance of two lines not in the same plane),

- geometric transformations in the plane and space,

- $\quad$ loci (e.g., the perpendicular bisector of a segment in the plane and in space, circle, sphere),

- $\quad$ application of angle functions in two dimensions and three dimensions (triangle and spherical triangle).

Let us examine some specific examples that might be considered in mathematics classes. 


\section{Geometric basic insertion concepts}

The basic insertion concepts of point, straight line, plane and space are the basis developing geometrical concepts, theorems and definitions.

The straight line, for example, acts analogously in the plane to how the plane acts in space (it is worth identifying and discussing the features that make up the analogy together with the students). Thus, we can conclude that the analogue of the straight line in space is the plane. We can also provide students with further formulation of theorems and definitions. For example, two straight lines intersect if they have exactly one mutual point, or two planes are intersecting if they have exactly one mutual straight line. The analogy concept here is the idea of overlapping points.

A further example of analogising a basic geometrical concept is the interpretation of distance. By the distance between two parallel lines, we mean the distance from one arbitrary point of the straight line to the other straight line. In the case of the distance between two parallel planes we mean the distance from one arbitrary point of the plane to the other plane. Here we formulate the analogy by extending the concept of distance.

The axis-mirroring concept is a similar example of geometric transformation. A geometric transformation is called axis mirroring when every point of a given straight line $t$ is self-mapped and it assigns the point $\mathrm{P}^{\prime}$ of the plane to every other point $\mathrm{P}$ in such a way that the perpendicular bisector PP' of the segment is precisely the $t$ axis. The geometric transformation is called mirroring to the plane when every point of a given plane $S$ is self-mapped and point $\mathrm{P}^{\prime}$ is assigned to every other spatial point $\mathrm{P}$ so that the section PP' would be perpendicularly bisected by the plane S.

The determination of geometrical locations in the plane and in space is the same as we have seen previously. Here again it is worth having the students formulate the question of the spatial analogue. Let us begin with a simple example:

Teacher: What is the geometrical location of those points in the plane that are equidistant from a given point?

Student: A circle.

Teacher: Now, define the spatial analogue of the question!

Student: What is the geometrical location of those points in space that are equidistant from a given point?

Teacher: That is right. What can that object be?

Student: A sphere. 
The student needs to think logically to answer these questions and even more carefully in the case of defining the analogues of more difficult geometrical locations: What is the geometrical location of those points in the plane that are equidistant from a given straight line? (A parallel straight-line pair). What is the geometrical location of those points in space that are equidistant from a given straight line? (An infinite right circular cylinder).

\section{Subdivision of 2-D and 3-D space}

One of the most difficult typical problems that can occur in the classroom is related to the subdivision of two and three dimensional space. These problems can be discussed together. The question is: A maximum of how many sections are created in the plane by $n$ number of straight lines? The spatial analogue formulation in this case is: A maximum how many sections are created in space by $n$ number of planes? The formulation of the problem itself is not difficult, but the students rarely succeed in finding a solution, especially in the case of using an analogue. An outline version of the deduction of the problem is shown in Figure 1.

\begin{tabular}{|c|c|}
\hline The division of planes with straight lines & The division of three dimensions with planes \\
\hline $\begin{array}{c}\qquad \begin{aligned} \mathrm{s}(1) & =\mathrm{s}(0)+1 \\
\mathrm{~s}(2) & =\mathrm{s}(1)+2 \\
\mathrm{~s}(3) & =\mathrm{s}(2)+3 \\
\ldots & \\
\mathrm{s}(\mathrm{n}) & =\mathrm{s}(\mathrm{n}-1)+\mathrm{n} \\
\mathrm{s}(\mathrm{n}+1) & =\mathrm{s}(\mathrm{n})+\mathrm{n}+1\end{aligned} \\
\text { Adding together the appropriate sides } \\
\text { of the above equation than sorted we } \\
\text { will get: } \\
\mathrm{s}(n)=\frac{1}{2}\left(n^{2}+n+2\right) \\
\text { A more easy to remember form: } \\
\qquad s(n)=\left(\begin{array}{l}n \\
0\end{array}\right)+\left(\begin{array}{l}n \\
1\end{array}\right)+\left(\begin{array}{l}n \\
2\end{array}\right)\end{array}$ & $\begin{array}{c}\mathrm{t}(1)=\mathrm{t}(0)+\mathrm{s}(0) \\
\mathrm{t}(2)=\mathrm{t}(1)+\mathrm{s}(1) \\
\ldots \\
\mathrm{t}(\mathrm{n})=\mathrm{t}(\mathrm{n}-1)+\mathrm{s}(\mathrm{n}-1) \\
\text { So } \\
\mathrm{t}(\mathrm{n})=\mathrm{t}(0)+\mathrm{s}(0)+\mathrm{s}(1)+\ldots+\mathrm{s}(\mathrm{n}-1) \\
\text { Therefore } \\
t(n)=\frac{1}{6}\left(n^{3}+5 n+6\right) \\
\text { A more easy to remember form: } \\
t(n)=\left(\begin{array}{l}n \\
0\end{array}\right)+\left(\begin{array}{l}n \\
1\end{array}\right)+\left(\begin{array}{l}n \\
2\end{array}\right)+\left(\begin{array}{l}n \\
3\end{array}\right)\end{array}$ \\
\hline
\end{tabular}

Figure 1. Subdivision of the plane and space.

Out of 47 students, there was only one who solved the spatial analogue problem successfully.

Textbooks (with some exemplary exceptions) do not even refer to spatial analogies, thus denying students an opportunity to understand analogues or read about them in mathematics classes. More talented students are forced into the background and their thought and abilities are suppressed. A spatial 
skill development study group session was introduced in the 2012-2013 school year. It took place once a week, resulting in total 36 study hours. Out of these 36 hours, plane-spatial analogies were taught for 16 hours, with an average of 10-12 students participating in each session. A qualitative-type test was performed with reference to these 16 hours. This test evaluated the attitude of the students about the topic and included an examination of affective psychosomatic factors. It also included the evolution of the rate of motivation, continuous observation of the students, student interviews and questionnaires, the attitudes of the participants to the problems, and the opinions of the students at the end of the session (regarding the change of approach and its development).

Let us examine the analogues that occurred in the study group sessions.

\section{Problems occurring at the study group sessions}

I believe that the following two dimensional analogies can be considered in study group sessions based on secondary school knowledge:

- triangle-tetrahedron,

- circle-sphere,

- $\quad$ parallelogram-parallelepiped (square-cube, rectangle-cuboid),

- trapeze, triangular-based truncated pyramid,

- coordinate geometric analogies,

- analogue entry and paraphrasing problems,

- $\quad$ analogue extreme value problems.

The scope of the present paper does not permit a full presentation of the study group material; instead, some analogies are illustrated in detail with student reactions and didactical comments. The analogies selected are those that would be the most interesting for students and that have a stronger link to standard mathematical material.

\section{A possible analogue of the cosine theorem}

The triangle-tetrahedron analogue is a huge and extensive topic, and is alone sufficient to occupy an entire study group session. Table 2 shows the related theorems and correlations in detail. 
Table 2. Triangle and tetrahedron analogies.

\begin{tabular}{|c|c|}
\hline $\begin{array}{l}\text { General triangles, } \\
\text { tetrahedrons }\end{array}$ & $\begin{array}{l}\text { Right triangle, } \\
\text { tetrahedron }\end{array}$ \\
\hline 3 bi-sectoral- 6 page bi-sectoral & First theorem of Euclide \\
\hline Inscribed circle inscribed sphere & Height theorem \\
\hline $\begin{array}{c}3 \text { side perpendicular bisector-6-edge and } \\
\text { section midpoint perpendicular bisector, } \\
\text { two dimensional object }\end{array}$ & Pythagorean theorem \\
\hline Added circle - added sphere & Euler-straight line \\
\hline $\begin{array}{l}\text { Radius formulas of circles-radius formulas } \\
\text { of sphere }\end{array}$ & Feurbach circle-Feurbach-sphere \\
\hline \multicolumn{2}{|l|}{ Sine theorem } \\
\hline Cosine theorem & \\
\hline
\end{tabular}

The average secondary school students were especially interested in the Pythagorean Theorem, the height theorem, the leg theorem, or the cosine and sine theorem. Let us examine the analogue of the cosine theorem in detail followed by some of the students' opinions regarding the theorem.

The cosine theorem related to the triangle is:

$a^{2}=b^{2}+c^{2}-2 b c \cos \alpha$,

where $a, b$ and $c$ are the length of the sides, and $\alpha$ is the angle opposite the side.

Let us consider two different types of proof, one algebraic and the other geometrical. It is important to show the students that we can approach the problem in a number of ways, all of which can lead to the correct solution, irrespective of the method used.

According to the algebraic proof, the following statements are true for any kind of triangle (acute angle, obtuse angle, right angle):

$$
\begin{aligned}
& a=b \cos \gamma+c \cos \beta, \\
& b=a \cos \gamma+c \cos \alpha, \\
& c=b \cos \alpha+a \cos \beta .
\end{aligned}
$$

Multiplying the first equation with $a$, the second with $b$ and the third with $c$, and adding the resulting equations together, we arrive at the solution.

Based on the vector-type proof, let us direct $a, b$ and $c$ side vectors such that we rotate around the triangle counter clockwise. In this case:

$a+b+c=0$,

and from this we get:

$a=-(b+c)$. 
If we then square both sides, i.e., self-multiply it in $a$ scalar way, we get: $a^{2}=b^{2}+2 b c+c^{2}$.

It should be known that the square of $a$ vector is equal to its absolute squared value. This follows from the scalar product definition. If we draw $a, b$ and $c$ vectors in line with their direction but from their mutual starting point, we can see that their angle of inclination is not $\alpha$, but $180^{\circ} \alpha$, thus the $a, b$ and $c$ vector's scalar product is:

$$
b c=b c \cos \left(180^{\circ}-\alpha\right)=-b c \cos \alpha .
$$

In the study group session, we developed the formulation and proof of the spatial analogue of the problem just mentioned. We had sufficient prior knowledge to be aware that in the special case of $\alpha=90^{\circ}$, i.e., in case of right triangle, the cosine theorem is provided by the Pythagorean Theorem; superficially, the cosine theorem can also be considered as a generalisation of the Pythagorean Theorem. We started from this point with the students, and they therefore had certain ideas about what the three-dimensional Pythagorean Theorem would look like.

Some of the ideas put forward by the students for the three-dimensional shape of the Pythagorean Theorem were:

$$
\begin{aligned}
& a^{3}+b^{3}=c^{3}, \\
& a^{3}+b^{3}+c^{3}=d^{3} .
\end{aligned}
$$

The first student could to try this problem not explain what $a, b$ and $c$ might indicate; and thought they could be the length of the edges. The second student got somewhat closer to the truth by stating that the letters could mean the areas of the 1-1 sheet of the tetrahedron. All 12 students agreed that in the three-dimensional Pythagorean Theorem the side variables $a, b$ and $c$ are raised to cube power. Let us look at the deduction:

Consider the generalisation of the cosine theorem related to the tetrahedron. If we mark the sheet areas of the tetrahedron with $t i(i=1,2,3,4)$, and if we mark the plane angle created by $t i$ and $t j$ sheet areas with $\alpha_{i j}(i, j=1,2,3,4$; $i \neq j$ ), we get:

$t_{1}^{2}=t_{2}^{2}+t_{3}^{2}+t_{4}^{2}-2 t_{2} t_{3} \cos \alpha_{23}-2 t_{2} t_{4} \cos \alpha_{24}-2 t_{3} t_{4} \cos \alpha_{34}$.

If the occurring angles are $90^{\circ}$, we get the following correlation:

$t_{1}^{2}=t_{2}^{2}+t_{3}^{2}+t_{4}^{2}$.

This is the Pythagorean Theorem related to the right angle tetrahedron. It was surprising to the students that the degree number of the formula 
remains 2 despite the spatial extension. They understood this better when considering the proof below:

Let us project perpendicularly the further three sheets to the plane of each tetrahedron sheet and determine the correlation between 1-1 sheet area and the area of the other sheets' incidental projection. This way, we get the following correlation:

$$
\begin{aligned}
& t_{1}=t_{2} \cos \alpha_{12}+t_{3} \cos \alpha_{13}+t_{4} \cos \alpha_{14}, \\
& t_{2}=t_{1} \cos \alpha_{12}+t_{3} \cos \alpha_{23}+t_{4} \cos \alpha_{24}, \\
& t_{3}=t_{1} \cos \alpha_{13}+t_{2} \cos \alpha_{23}+t_{4} \cos \alpha_{34}, \\
& t_{4}=t_{1} \cos \alpha_{14}+t_{2} \cos \alpha_{24}+t_{3} \cos \alpha_{34} .
\end{aligned}
$$

We can easily check that these correlations are true in each case, even if there are obtuse and right angles among the plane angles of the tetrahedron. If the above equation is multiplied by $t_{1}-,\left(-t_{2}\right)-,\left(-t_{3}\right)$ - and $\left(-t_{4}\right)$ respectively, adding the given equations together we arrive at the correct formula.

In accordance with the plane theorem, the proof with vectors works here as well. We have seen that the sum of the side length vectors of the triangle is a null vector. The spatial equivalent of this is the following statement: The sum of the sheet area vectors of the tetrahedron is a null vector. A sheet area vector belongs to every sheet of the tetrahedron. This is a vector whose size is equal to the area of the sheet and whose direction is perpendicular to the sheet pointing outwards. From this principle, we will deduce the cosine theorem of the tetrahedron.

After the deduction, the students judged the formula to be logical and also understood why we do not have to increase the number of degrees in the exponents. The next step was the collection and solution of specific analogue problem pairs. The students were more successful in this than in the theoretical background deduction.

\section{Circle-sphere analogies}

From the circle-sphere analogues, the following can come into the picture at the study group session:

- $\quad$ similarity points,

- Apollonius-type problems,

- inversions,

- the power of a point concerning circles and spheres,

- lines of circles, lines of spheres,

- $\quad$ circle crowds with one parameter and their spatial analogue.

The most familiar of these is the inversion. The fact that there are rather "strange" geometric transformations could also be interesting to students. The 
interpretation of the inversion is: The inversion maps regarding a circle with centre $O$ and radius $r$ so that in the plane it transfers point $P$ differing from any point $O$ of the plane to point $\mathrm{P}^{\prime}$ on the half-straight line of $O P$, and for which the following is true $O P \cdot O P^{\prime}=r^{2}$.

Using a couple of examples, let us analyse the concrete construction method, and then let the students formulate the definition of the spatial analogue based on the concept of an inverted plane Here is an example of the correct wording of a student: The inversion related to a sphere with centre $O$ and radius $r$ maps so as to transfer point $\mathrm{P}$ differing from any point $\mathrm{O}$ in space to point $P^{\prime}$ on the $O P^{\prime}$ half line. For this statement, the equation $O P \cdot O P^{\prime}=r^{2}$ is true.

The formulation of the spatial analogue is very clear and occurred naturally to the students. The representation of the exact problem was performed with the help of GeoGebra (discussed in more detail in the next section).

After the constructions and discussions for the different objects and locations are made in GeoGebra, the students can easily compose a few theorems related to the inversion:

T1: the straight line going through the pole (plane) is the inverse of itself, T2: the straight line not going through the pole (plane)-its inverse is the circle going through the pole (sphere),

$\mathrm{T}_{3}$ : the circle going through the pole (sphere)-its inverse is the straight line not going through the pole (plane),

T4: the circle not going through the pole (sphere)-its inverse is the circle not going through the pole (sphere),

T5: there are many such circles (spheres) for which the inverses are themselves.

After this, we discussed the inversion from the perspective of coordinate geometry. The plane theorem is as follows: If the equation of the plane inversion of the base circle is $x^{2}+y^{2}=1$, then the inverse of the arbitrary point $P(x, y)$ differing from the plane pole, is:

$$
P^{\prime}\left(\frac{x}{x^{2}+y^{2}}, \frac{y}{x^{2}+y^{2}}\right) \text {. }
$$

The three-dimensional analogue formulation can be considered as a problem of medium difficulty. 7 of the 12 students were able to formulate correct spatial analogue theorems. A perfect formulation by a student is as follows: If the equation of a base circle's spatial inversion is $x^{2}+y^{2}+z^{2}=1$, then the inverse of the arbitrary point $P(x, y, z)$ differing from the pole is:

$$
P^{\prime}\left(\frac{x}{x^{2}+y^{2}+z^{2}}, \frac{y}{x^{2}+y^{2}+z^{2}}, \frac{z}{x^{2}+y^{2}+z^{2}}\right) \text {. }
$$


In our experience, the degree of the exponents does not necessarily change when setting up the plane-spatial (two dimensional) analogue.

The students participating in the study group sessions really liked the inversion; they found it extraordinary compared to the familiar geometric transformations. They prepared and collected several theorem pairs to be studied at home. One student said the following about the inversion: "It is fantastic that we can close the whole world into a circle/sphere."

\section{Parallelepiped and parallelogram analogues}

The parallelepiped and parallelogram analogues can be very colourful; we can even consider special cases originating from the definitions, such as square-cube or rectangular-cuboid. In the case of the formulation of the theorems, we aimed for the more ordinary features, ( $p$ marks the parallelogram and $P$ the parallelepiped):

T1: $p$ and $P$ are centrally symmetric,

T2: any two opposite sides of $p$ are equal length, any two opposite sheets of $P$ are congruent,

T3: $p$ 's and $P$ 's centre of gravity and their centre of symmetry coincide,

T4: the opposite angles of $p$ are equal, $P$ 's opposite plane angles are equal, $\mathrm{T}_{5}$ : any straight line going through the symmetry centre (plane) splits the area of $p$ (the volume of $P$ ) in half.

The students were able to understand the above theorems. However, if problems are encountered it is worth using the aforementioned special cases, thus gradually introducing the use of analogue theorem pairs. Let us consider the following problem in the plane. The ratio of the sides of a rectangle is 2:1, and the ratio of numbers for its circumference and area are equal. How large are the sides of the rectangle?

Teacher: What could the problem pair of the spatial analogue be? Try to formulate it.

Student's train of thought:

rectangle $\rightarrow$ cuboid

the ratio of the sheets is $1: 2$ and the $\rightarrow$ ratio of the edges is $1: 2: 3$,

circumference $\rightarrow$ surface,

area $\rightarrow$ volume.

This is an example of the independent creation of an analogue problem pair by a student. Quite rightly, he placed every concept in the problem into the 
next higher dimension, thus reaching a spatial analogue. This type of problem aims to develop an important competence for finding similar problems.

\section{Coordinate geometry}

Let us examine a typical classroom example from the topic of coordinate geometry: an equation of a straight line. Below are the analogues of the direction vectored equation for the planar and spatial straight line:

- The plane equation of the straight line that goes through point $P_{0}\left(x_{0}, y_{0}\right)$, with a direction vector $v\left(v_{1}, v_{2}\right)$ is:

$v 2\left(x-x_{0}\right)=v_{1}\left(y-y_{0}\right)$

- The equation system for the spatial straight line with a direction vector $v\left(v_{1}, v_{2}, v_{3}\right)$, going through point $P_{0}\left(x_{0}, y_{0}, z_{0}\right)$ is:

$V_{2}\left(x-x_{0}\right)=v_{1}\left(y-y_{0}\right)$,

$V_{3}\left(y-y_{0}\right)=v_{2}\left(z-z_{0}\right)$.

After a discussion of the theory, the solution of a specific problem was considered. What is the equation of the straight line that goes through point $(3,-2)$ and is perpendicular to the straight line with the equation $5 x+6 y+1$ ?

This problem is a typical classroom problem required for graduation. Let us place this problem into space, and then the task of the students is to find a spatial analogue problem (What is the equation of the straight line that goes through point $(3,-2,1)$ and is perpendicular to the straight line with the equation?) and to work out its solution based on the experience already gathered.

\section{Extreme value}

Finally, let us examine a problem related to extreme value calculations. This is a typical example of how analogical thinking can play a role in the solution of a problem, specifically:

- $\quad$ setting up and solving a simpler analogue problem,

- $\quad$ showing how the more difficult problem can be solved if the sample problem is reshaped to a certain degree.

Problem: Let us fix the base of a regular three-sided pyramid and change its height $\mathrm{m}$. Let us select the value of $\mathrm{m}$ such that the radius of a sphere drawn around the pyramid would be the smallest possible!

This problem was solved in one of the later study sessions when the students had already acquired insight into analogue based problem solving. At 
first, they looked for a simpler solution, i.e., the analogue of the original problem in two dimensions. After having solved this and discussed the solution, they returned to the original problem and applied the related (spatial) theorems, knowledge based on the problem solved in the plane (two dimensions).

A possible formulation of a simple plane problem by a student is: Let us fix the base of an isosceles triangle and change its height $m$ ! What size of $m$ will produce the smallest possible radius of the circle drawn around the triangle?

In summary, we discuss a plane problem with the students and then present a spatial analogue of that problem with a variety of proof methods. After the similar properties are found in the plane and space analogues, the students themselves search independently for further similar properties. Then there is a discussion of the concrete problem related to the plane and the spatial analogies, followed by the collection and elaboration of the analogue problem pairs.

\section{Development using GeoGebra}

Several recent research studies indicate that we can achieve better results in mathematics classes with the use of GDS than with traditional mathematics tools. Version 4.2 of GeoGebra does not include the display of spatial objects, but after defining one's own base system it is possible to display such objects. Version 5.o Beta is still undergoing significant development, and under certain conditions its operation may therefore be unstable. Taking all of this into consideration, the best solution is to become familiar with both versions.

Let us briefly examine some examples, without attempting to be comprehensive.

The simplest approach is to demonstrate the conventional plane geometric transformation's spatial analogue (Figure 2).

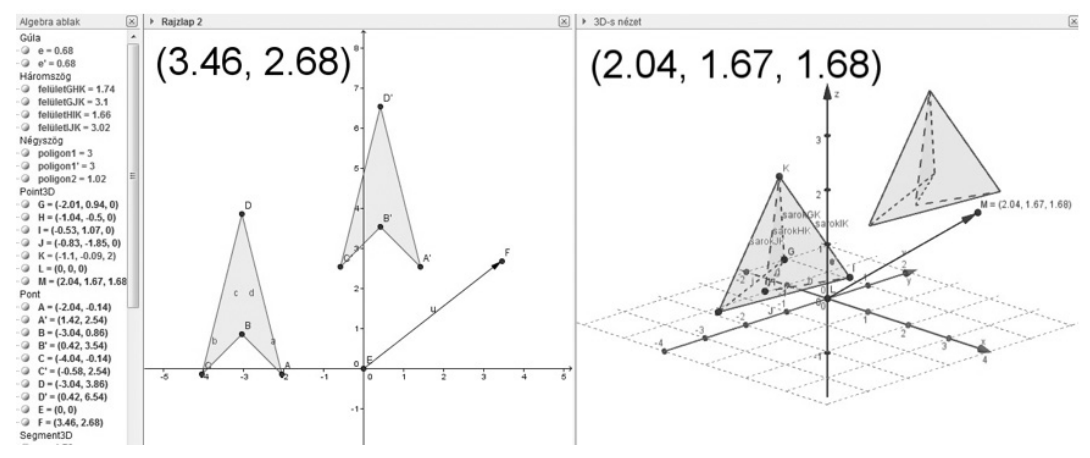

Figure 2. Analogue of plane and space translation. 
GeoGebra offers many possibilities, allowing the user to work in more than one window at the same time. The algebra window contains the equations of the selected objects and both a plane worksheet and a spatial worksheet are displayed. We can work in these three windows simultaneously, and if we change a feature in one window it dynamically changes in the other windows, although it is also possible to disable this feature. Another very important feature is that we can choose from a variety of projections; for example, we can select how we would like to display the spatial object in a plane (parallel projection, axonometries), thus broadening the approach related to the spatial skills of students.

We can modify any features interactively and dynamically, even in the case of translation (Figure 2). In addition to working in the classroom, it can be very useful to develop a self-learning environment in which the student him/ herself can discover correlations. The coordinates may be written out, which is useful for those who find it easier to understand or associate in this way.

The presentation of proofs is very valuable for classroom use. For example:

$$
\begin{aligned}
& (a+b)^{2}=a^{2}+2 a b+b^{2} \text { and } \\
& (a+b)^{2}=a^{2}+3 a^{2} b+3 a b^{2}+b^{2} .
\end{aligned}
$$

Students always have problems with the sameness of algebraic equations; for example, the double product is often left out. Instead of mechanically memorising the formula, they see graphic evidence dynamically, enabling them to understand the origin of the double product. For spatial cases, this exists exponentially (Figure 3).
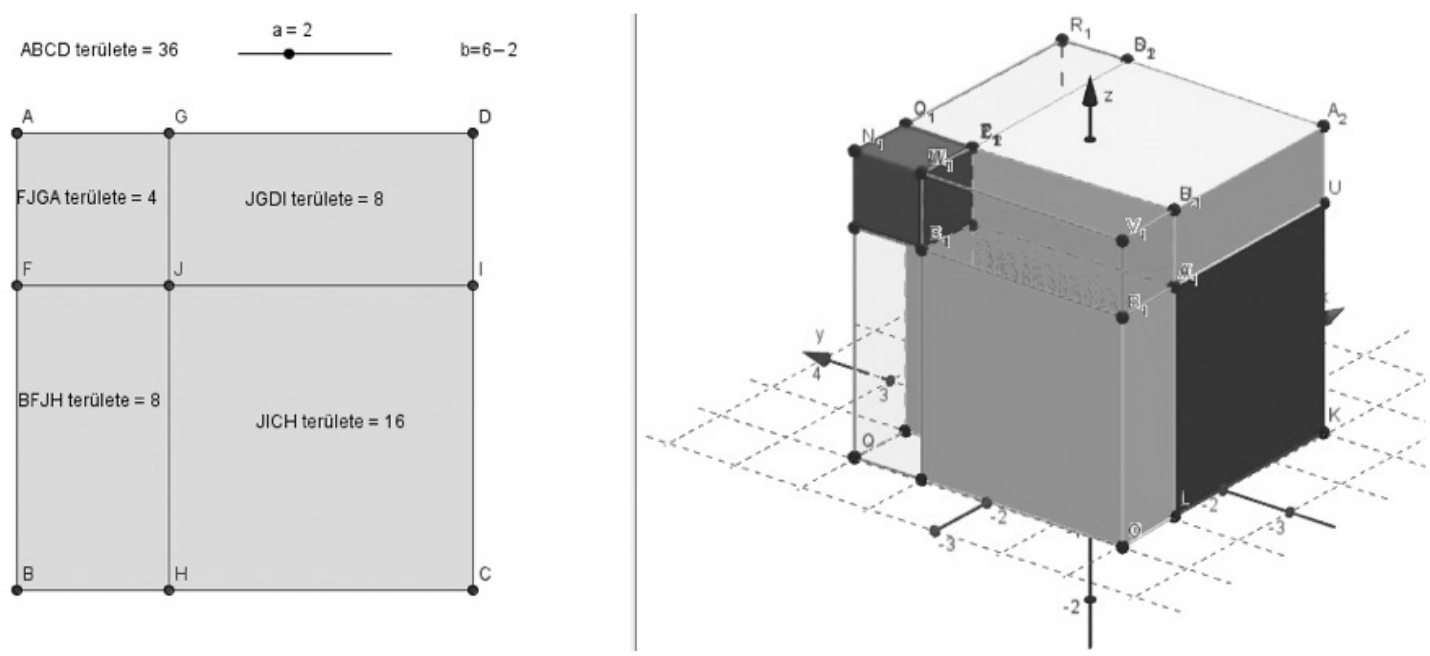

Figure 3. Algebraic proof of sameness in plane and space. 
Students can set up the subdivisions dynamically, i.e., the value of $a$ and $b$. By adjusting these parameters to the levels of volume and area extent, they can then also read them dynamically. After the subdivisions have been made, we can see what kinds of shapes were created and how it generates the whole square/cube. Remembering the formula was much easier for students this way.

The first major challenge of the study group session was to discover the cosine theorem's analogue. As we saw in the previous section, it is worth considering a special case, namely the Pythagorean Theorem (Figure 4).

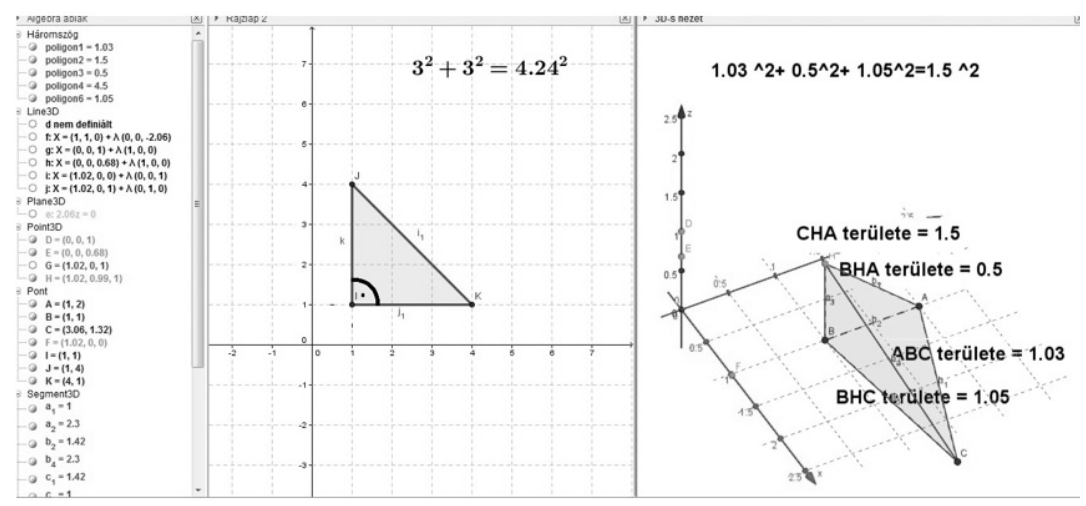

Figure 4. Plane and space analogues of the Pythagoras theorem.

We can see in Figure 4 that the correlation is given by the squared sum of the appropriate areas. The students can attempt the correlation even in the case of more values by moving the vertexes with the help of the dynamic figure. They can even determine the equation of the spatial analogue independently. By moving the respective vertex point, a general tetrahedron can be obtained instead of a right triangle tetrahedron. This allows the cosine theorem correlations to be derived, a problem more complicated for students.

The students participating in the study group sessions particularly liked the inversion, since they had not met such transformations directly in their everyday lives. Figure 5 shows a possible GeoGebric adaptation of this transformation.

The inversion in the plane exists as a built-in option in GeoGebra 4.2. If we extend this, we have an opportunity to present the spatial inversion to students, a task that would be very cumbersome using traditional spatial tools. The analogue features are clearly visible in the figure and the students can independently read the major theorems. While using the worksheet, the plane and spatial geometric windows were connected; therefore, if we move the straight line of the plane figure, the plane of the spatial figure moves at the same rate. Of course, it is also possible to handle the worksheets separately. 

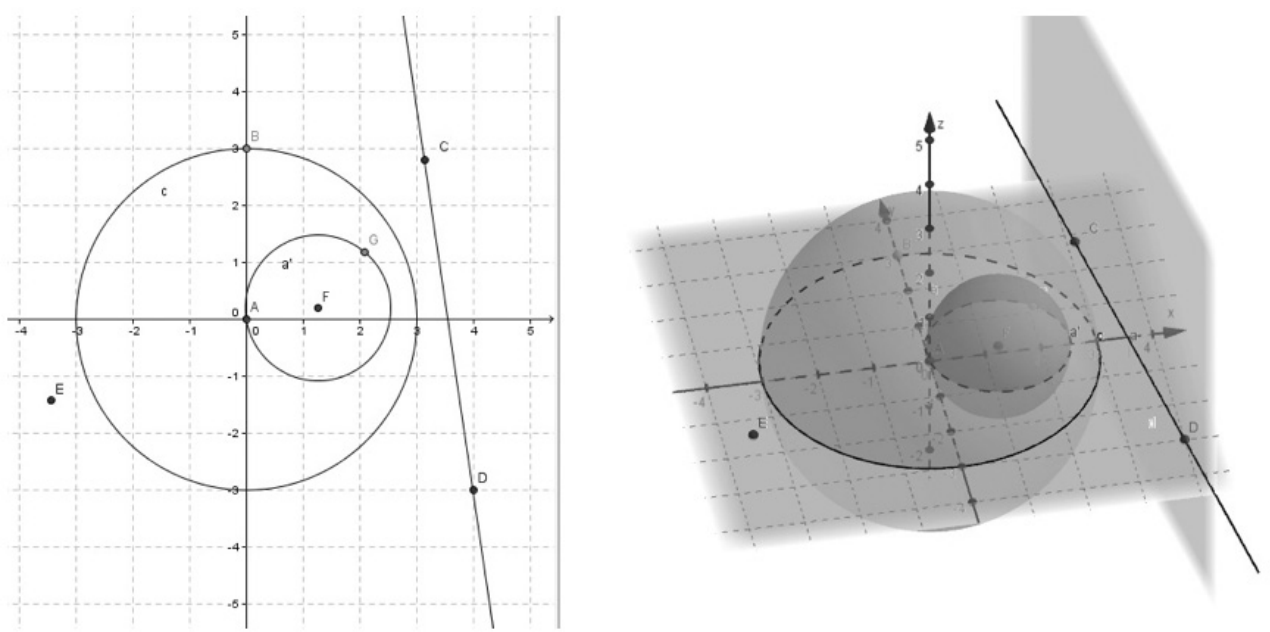

Figure 5. Plane and spatial analogues of inversions.

The plane and spatial analogues of coordinate geometry can be presented richly with the help of GeoGebra, since part of the concept of GeoGebra is to show the algebraic and geometric view of the objects in parallel. Several possibilities may arise here: the extension of the coordinates of points to spatial cases, the equations of straight lines in the plane and space, the equations of circles in the plane and space, the equation of a sphere, equations of surface areas and curves and the determination of intersections (just one click in GeoGebra!).

Last but not the least, let us examine the calculation of the extreme value. Here the students may apply GeoGebra very effectively, as they have an opportunity to quickly prepare the figures that suit the different conditions and then formulate the conjecture (Figure 6).

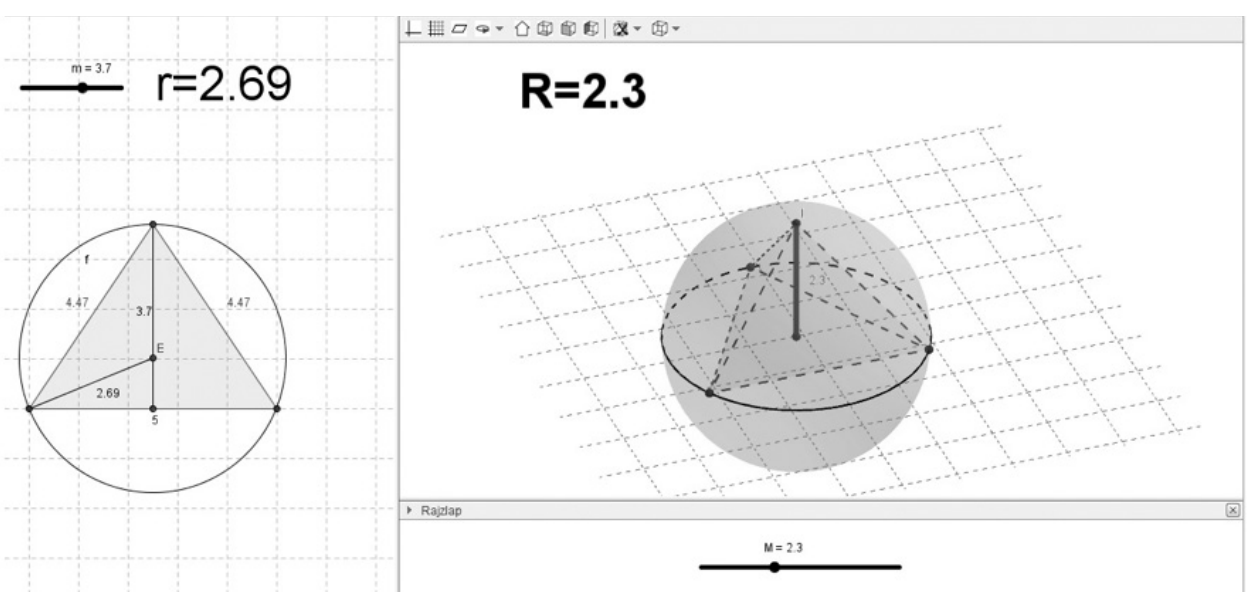

Figure 6. Extreme value calculation, example of searching for and solving simple analogue problems. 
In this case, it is worth separating the worksheets from each other, i.e., the planar and spatial analogue problems should be moved separately.

Using GeoGebra to solve the 2-D analogue of the previous problem he students realized that the radius of a circle around the triangle is smallest when its diameter is equal to the base of the triangle, i.e., $r=a / 2$ and then $m=a / 2$.

The students could then return to solving the more difficult analogue problem, and again with the help of GeoGebra formulate their conjectures. The sphere drawn around each and every joint based pyramid goes through the vertexes of the joint base sheet, i.e., it fits on the circle drawn around the joint base sheet.

Of these spheres, the smallest is the one whose main circle is the circle drawn around the base sheet, i.e., $r=(a \sqrt{3}) / 2 \cdot 2 / 3=(a \sqrt{3}) / 3$, and the height is also this length.

By their own admission, GeoGebra helped the students a great deal in solving and analysing the problems. After finding the basic ideas necessary to solve the problems, the search for the analogue problem pairs was simpler. The students successfully used dynamic sketch drawings in GeoGebra and were able to analyse and discuss solutions to the problems.

\section{Conclusion}

In my experience based on the responses of the students who participated in the study group sessions the discussion of analogues provides an excellent opportunity to develop problem-solving skills. The analogue mindset helps students handle the problem with a different approach. Presenting the proofs may also enable students to absorb different proof strategies. Studying analogue problem pairs, developing new pairs, and solving them promotes understanding and use of analogues. In the case of more difficult problems, the approach can be further facilitated by solving a simpler but similar type of problem first and then returning to the original more difficult problem.

In summary, the following observations were made at the study group sessions.

The students who participated in the study group sessions could do the following well:

- $\quad$ formulating spatial analogue problems and theorems,

- $\quad$ stating attributes of plane objects that are related to their spatial analogue,

- $\quad$ solving problems using the knowledge related to spatial analogues,

- choosing the suitable supplementary tools for solving the 1-1 analogue problem. 
The students who participated in the study group sessions could not do the following very well:

- $\quad$ formulating notable triangle theorem analogues independently,

- $\quad$ proving spatial theorem analogues based on plane theorems (even if they knew the basic ideas).

Based on the qualitative-type surveys, the study group sessions were useful for the participants. The wide range of possible uses of analogues may help students to develop their cognitive operation and creativity, encouraging:

- independent ideas for possible analogues,

- $\quad$ increased student motivation for the correct justification of ideas

- $\quad$ the use of IT tools (GeoGebra 5.0).

Analogies help the students with problem solving, developing their creative response and contributing to the retention of new information. These two functions are fulfilled by helping users to think in new ways and facilitate the acquisition of abstract concepts.

\section{Acknowledgements}

I would like to express my particular gratitude for the help of Miklós Hoffmann, Ján Gunčaga and András Ambrus.

\section{References}

Cižmešija, A., \& Milin-Šipuš, Ž. (2012). Spatial ability of students of mathematics education in Croatia evaluated by the Mental Cutting Test. Annales Math. et Inf., 40, 203-216.

Gorska, R., \& Jušcakova, Z. (2007). TPS Test Development and Application into Research on Spatial Abilities. Jour. Geom. Graph., 11, 223-236.

Hoffmann, M., Németh, B., \& Sörös, Cs. (2007). Typical Mistakes in Mental Cutting Test and Their

Consequences in Gender Differences. Teaching Mathematics and Computer Science, 5(2), 385-392.

Hoffmann, M., \& Németh, B. (2006). Gender differences in spatial visualization among engineering students. Annales Mathematicae et Informaticae, 33, 169-174

Leclére, P., \& Raymond, C. (2010). Use of the GeoGebra software at upper secondary school, FICTUP Public case report, INPL, France.

Lénárd, F. (1978). A problémamegoldó gondolkodás. Budapest: Akadémiai Kiadó.

Lord, T. R. (1985). Enhancing the Visuo-spatial Aptitude of Students. Journal of Research in Science Teaching, 22, 395-405.

McGee, M. G. (1979). Human Spatial Abilities: Psychometric studies and environmental, genetic, hormonal and neurological influences. Psychological Bulletin, 86, 899-918. 
Nagy-Kondor, R. (2007). Spatial ability of engineering students. Annales Mathematicae et Informaticae, 34, 113-122.

Nagy-Kondor, S. (2012). Engineering students' spatial abilities in Budapest and Debrecen. Annales Math. et Inf., 40, 187-201.

Nagy-Kondor (2010). Spatial Ability, Descriptive Geometry and Dynamic Geometry Systems.

Annales Math. et Inf., 37, 199-210

Nagy, L. (2000). Analógiák és az analógiás gondolkodás a kognitív tudományok eredményeinek tükrében. Magyar Pedagógia.

Pólya, Gy. (1985). A problémamegoldás iskolája I. Budapest: Typotex Kft.

Pólya, Gy. (1988). A gondolkodás iskolája. Budapest: Typotex Kft.

Pólya, Gy. (1988). A problémamegoldás iskolája II. Budapest: Typotex Kft.

Pólya, Gy. (1989). A plauzibilis következtetés. Budapest: Gondolat Kiadó.

Pólya, Gy. (1989). Indukció és analógia. Budapest: Gondolat Kiadó.

Reiman, I. (1986). A geometria és határterületei. Budapest: Gondolat Kiadó.

Schröcker, H.-P., Stachel, H., Tsutsumi, E., \& Weiss, G. (2005). Evaluation of Students' Spatial

Abilities in Austria and Germany. Jour. Geom. Graph., 9, 107-117.

\section{Biographical note}

LÁszLó BUDAI is a PhD students of Mathematics and Computer Sciences at the University of Debrecen (Hungary). He was a mathematic-IT teacher, till 2013 a research assistant, instructor at Budapest Business School, University of Applied Sciences, College of International Management and Business, Institute of Business Teacher Training and Pedagogy. His research interests are in Spatial geometry and GeoGebra methodology applications. His current projects is GeoMatech. 